\title{
Global trend of Plasmodium malariae and Plasmodium ovale spp. malaria infections in the last two decades (2000-2020): a systematic review and meta-analysis
}

\author{
Joseph Hawadak ${ }^{1 \dagger}$, Rodrigue Roman Dongang Nana ${ }^{1,2+}$ and Vineeta Singh ${ }^{1 *}$ (B)
}

\begin{abstract}
Background: Recent studies indicate that the prevalence of non-falciparum malaria, including Plasmodium malariae and Plasmodium ovale spp., is increasing, with some complications in infected individuals. The aim of this review is to provide a better understanding of the malaria prevalence and disease burden due to P. malariae and P. ovale spp.

Methods: The Preferred Reporting Items for Systematic Reviews and Meta-Analyses (PRISMA) guidelines and the Joanna Briggs Institute prevalence study assessment tool were used to select and evaluate the studies, respectively. Six databases: PubMed, WHOLIS, Wiley Library, ScienceDirect, Web of Science and Google Scholar were used to screen articles published during the period January 2000-December 2020. The pooled prevalence estimates for P. malariae and $P$. ovale spp. were analysed using a random-effects model and the possible sources of heterogeneity were evaluated through subgroup analysis and meta-regression.

Results: Out of the 3297 studies screened, only 113 studies were included; among which 51.33\% were from the African Region. The P. malariae and P. ovale spp. pooled prevalence were $2.01 \%(95 \% \mathrm{Cl} 1.31-2.85 \%)$ and $0.77 \%(95 \% \mathrm{Cl}$ $0.50-1.10 \%)$ respectively, with the highest prevalence in the African Region. P. malariae was equally distributed among adults $(2.13 \%)$, children $(2.90 \%)$ and pregnant women $(2.77 \%)(p=0.862)$, whereas $P$. ovale spp. was more prevalent in pregnant women $(2.90 \%)$ than in children $\leq 15$ years $(0.97 \%)$ and in patients $>15$ years old $(0.39 \%)(p=0.021)$. In this review, data analysis revealed that P. malariae and P. ovale spp. have decreased in the last 20 years, but not significantly, and these species were more commonly present with other Plasmodium species as co-infections. No difference in prevalence between symptomatic and asymptomatic patients was observed for either $P$. malariae or $P$. ovale spp.
\end{abstract}

Conclusion: Our analysis suggests that knowledge of the worldwide burden of $P$. malariae and $P$. ovale spp. is very important for malaria elimination programmes and a particular focus towards improved tools for monitoring transmission for these non-falciparum species should be stressed upon to deal with increased infections in the future.

Keywords: Malaria infections, Plasmodium malariae, Plasmodium ovale spp., Prevalence, Meta-analysis

${ }^{*}$ Correspondence: vineetas_2000@yahoo.com

†Joseph Hawadak and Rodrigue Roman Dongang Nana contributed equally to this work

${ }^{1}$ ICMR-National Institute of Malaria Research, Dwarka, Sector 8, New-Delhi 110077, India

Full list of author information is available at the end of the article

\section{Background}

Malaria is an infectious disease caused by parasites of the genus Plasmodium and transmitted by infected Anopheles female mosquitoes in tropical and subtropical countries. This disease is a major public health problem globally, with 229 million estimated cases in 2019 , mostly

c) The Author(s) 2021. This article is licensed under a Creative Commons Attribution 4.0 International License, which permits use, sharing, adaptation, distribution and reproduction in any medium or format, as long as you give appropriate credit to the original author(s) and the source, provide a link to the Creative Commons licence, and indicate if changes were made. The images or other third party material in this article are included in the article's Creative Commons licence, unless indicated otherwise in a credit line to the material. If material is not included in the article's Creative Commons licence and your intended use is not permitted by statutory regulation or exceeds the permitted use, you will need to obtain permission directly from the copyright holder. To view a copy of this licence, visit http://creativeco mmons.org/licenses/by/4.0/. The Creative Commons Public Domain Dedication waiver (http://creativecommons.org/publicdomain/ zero/1.0/) applies to the data made available in this article, unless otherwise stated in a credit line to the data. 
in African and South-East Asia regions [1]. Several international programmes have been launched to reduce and/ or eradicate malaria worldwide, and considerable progress has been made over the past two decades, resulting in a decrease in the global incidence of malaria from 363 to 225 cases per 1000 population during the years 2000 to 2019 [1]. Unfortunately, recent reports of the emergence of artemisinin resistance in South-East Asia in the Greater Mekong Subregion adds another challenge hindering the efforts of malaria control programmes [2-4].

Among all human Plasmodium spp., P. falciparum and $P$. vivax receive particular scientific research interest, as they are responsible for the majority of malaria infections and disease severity in human patients, whereas $P$. ovale spp. and $P$. malariae remain neglected tropical diseases due to their low prevalence and still lower disease severity as compared to falciparum malaria $[3,5,6]$. The clinical features due to $P$. malariae and $P$. ovale spp. are thus poorly known, as very few reported studies are available compared to other human Plasmodium spp. [7]. P. ovale spp. are recognized to generally induce weak parasitaemia in the infected host, are very often responsible for relapses and sometimes have also been identified in certain renal complications [8]. In recent years, a steady rise in malaria infection cases associated with $P$. ovale spp. and $P$. malariae has been observed in many parts of subSaharan Africa and South America, with their prevalence being around $10 \%$ and $20 \%$, respectively, in both symptomatic and asymptomatic malaria infections, causing concern for elimination programmes [9-14]. This increase in prevalence underscores the need for attention towards them, and therefore knowledge about their demographic distribution and associated morbidity is essential for understanding their epidemiology. In this review article, we have focused on estimating the disease burden and the epidemiological aspects of malaria infections caused by $P$. malariae and P. ovale spp., highlighting the need for increased attention towards these species for successful malaria elimination programmes.

\section{Methods}

\section{Search strategy}

The Preferred Reporting Items for Systematic Reviews and Meta-Analyses (PRISMA) guidelines were used to select studies for this review [15], and six databases (PubMed, WHOLIS, Wiley Library, ScienceDirect, Web of Science and Google Scholar) were explored to access articles (Additional file 1). Although the search strategy differs slightly from one database to another, a systematic computerized strategy was adopted using MeSH terms and in combination with Boolean operators: ["malaria" OR "Plasmodium" AND ("malariae" OR "ovale" OR "curtisi" OR "wallikeri") AND ("prevalence" OR "epidemiology" OR "proportion" OR "frequency") AND ("PCR" OR "molecular")] (Additional file 2). In addition, a manual Google search and filtering of the reference lists of included studies were performed to access additional articles. The search included articles in both English and French languages published between January 2000 and December 2020.

\section{Selection of studies and data extraction}

All epidemiological studies that reported the prevalence of $P$. malariae and $P$. ovale spp. using molecular techniques as a species identification method were considered in this review. Only research articles published in peer-reviewed journals were included, and studies with no clear epidemiological data on Plasmodium spp. were excluded from the review. All articles were imported into Zotero bibliographic reference management software, and duplicate files were deleted. A data extraction form with the name of the first author, year of publication, period of data collection, geographical location (continent and country), target group (subject and subject status), type of study, sample size, sampling technique, diagnostic method, target gene and a positive result for each human Plasmodium species was prepared in a Microsoft Excel spreadsheet. The data files extracted independently by the first two authors were systematically evaluated for any inconsistencies, and any further discrepancies were resolved after discussion with the team supervisor.

\section{Evaluation of criteria for inclusion of studies}

The quality and risk of bias in included studies were assessed using an adapted version of the Joanna Briggs Institute (JBI) prevalence study assessment tool [16]. The evaluation criteria were based on eight parameters: (i) appropriate sample frame, (ii) appropriate sampling technique, (iii) adequate sample size, (iv) description of the study subject and settings in detail, (v) sufficient data analysis, (vi) use of validated methods for the conditions identified, (vii) valid measurement of the condition for all participants and (viii) use of appropriate statistical analysis. For each evaluation item, a score of 1 was awarded if found in the article; zero was given if not, and no score if the evaluation tool was unclear or not applicable to the study. Studies that received a score $\geq 5$ were considered acceptable for final inclusion in the study (Additional file 3: Table S1).

\section{Data analysis}

Data analysis was performed with Metaprop command [17] in Stata 16.1 software (StataCorp LLC, USA). The combined prevalence and 95\% confidence intervals (CIs) were computed using a random-effects model 
with Freeman-Tukey double arcsine transformation and restricted maximum likelihood method for stabilization and estimating the covariance. Heterogeneity between studies was assessed using $I^{2}$, whose values of $25 \%, 50 \%$ and $75 \%$ were considered as low, moderate and high degrees of heterogeneity, respectively. The risk difference (RD) was performed to compare the occurrences of $P$. malariae/P. ovale spp. in mono-infections and coinfections with other species using OpenMeta[Analyst] software. Publication bias was also assessed using a funnel diagram by visually inspecting the plots and exact Egger's test for small-study effects. Possible sources of heterogeneity were assessed using subgroup analysis and meta-regression. We computed a subgroup analysis including only studies conducted in defined groups: (i) pregnant women, (ii) children $\leq 15$ years old and (iii) participants $>15$ years old. In the pregnant women group, when several samples were taken (peripheral blood, umbilical cord and/or placenta), only the results of the peripheral blood were used in the meta-analysis. A meta-regression with the sample size, date of publication and period of data collection as a covariate was performed to evaluate whether they were confounders of the $P$. malaria and/or $P$. ovale spp. pooled prevalence. All statistical analyses were considered statistically significant for values of $p<0.05$.

\section{Results}

\section{Study selection and identification}

A total of 3297 citations were screened initially, where 3278 were obtained from the six selected databases and 19 others through the manual Google search for inclusion in this review study. Five hundred and fortysix were duplicates and hence deleted. From the 2751 remaining articles, 2155 were excluded after reviewing the abstract. and a further 451 studies were excluded for one of the following reasons: (i) no access to the full text $(n=32)$, (ii) article in a language other than English or French $(n=4)$, (iii) epidemiological data on imported malaria cases $(n=46)$, (iv) comparative studies or diagnosis made by a new method $(n=19)$ and $(\mathrm{v})$ not related to our study framework $(n=350)$. Of the remaining 145 articles, 32 were excluded because of their methodology or a lack of epidemiological information (Additional file 3: Table S2). Finally, 113 studies involving 195,065 subjects were considered for the systematic review (Fig. 1). Ninety-five and 102 studies were included in quantitative analysis of $P$. ovale spp. and $P$. malariae prevalence, respectively. The characteristics of the studies included in this review are summarized in Additional file 3: Table S3.

\section{Characteristics of the included studies}

Of the 113 studies included in our review, more than half $(51.33 \% ; n=58)$ were published within the last 5 years, but no study was published in the year 2003 (Fig. 2a). The epidemiological studies included in this review covered five out of six pre-classified World Health Organization (WHO) health regions, with the African Region (AFR) accounting for half of the studies (57/113), followed by the Western Pacific (WPR) and South-East Asia regions (SEAR) with $21.24 \%$ (24/113) and 15.93\% (18/113), respectively (Fig. 2b). The smallest and largest study samples had 47 and 17,765 participants, respectively, with an average sample size of 1726 (interquartile range [312-1724]). Studies from AFR $(n=17,765)$, the Eastern Mediterranean (EMR) $(n=16,075)$ and WPR $(n=13,980)$ reported the largest sample size (Additional file 3: Table S3). Forty-nine studies (43.36\%) comprised both symptomatic and asymptomatic participants, whereas $26.55 \%$ and $30.09 \%$ included respectively asymptomatic and symptomatic participants only. Children under 15 years old were targeted in $10.62 \%$ of studies, mostly in AFR $(n=11)$; pregnant women were investigated in $7.08 \%$ in the African Region $(n=7)$ [18-24] and Region of the Americas (AMR) $(n=1)$ [25], and one study $(0.88 \%)$ was conducted among 4570 women of childbearing age in the Democratic Republic of the Congo (DRC) [26] (Additional file 3: Table S3).

All included studies used molecular diagnostic methods including nested polymerase chain reaction (PCR) (71.43\%), real-time polymerase chain reaction (RTPCR) (10.71\%), quantitative polymerase chain reaction (qPCR) (4.46\%) and loop-mediated isothermal amplification (LAMP) (3.54\%) for Plasmodium spp. identification. Nested PCR with four pairs of species-specific primers ( $P$. falciparum, $P$. vivax, $P$. malariae and $P$. ovale spp.) were seen in the majority of studies $(n=108)$, and a few also used $P$. knowlesi-specific primers for species identification and confirmation [27-31]. Only $7.07 \%$ of the studies used sympatric species-specific primers of $P$. ovale curtisi and $P$. ovale wallikeri $[9,10,21,32-36]$. The target genes for the PCR assay were mainly $18 \mathrm{~S}$ rRNA (83.19\%), cytochrome b $(9.73 \%)$ and plasmepsin $4(1.17 \%)$ genes [33, 37]. One study from South-East Asia targeted 18S rRNA and cytochrome b genes simultaneously [38] (Additional file 3: Table S3).

\section{$P$. malariae and $P$. ovale spp. prevalence}

The aggregate prevalence of $P$. malariae in the 102 studies using the random-effects model was $2.01 \%$ (95\% CI $1.31-2.85 \%, \operatorname{tau}^{2}=0.07$ ), with high and significant heterogeneity between the studies $\left(I^{2}=99.19 \%, p<0.001\right)$. In comparison to $P$. malariae, the prevalence of $P$. ovale 


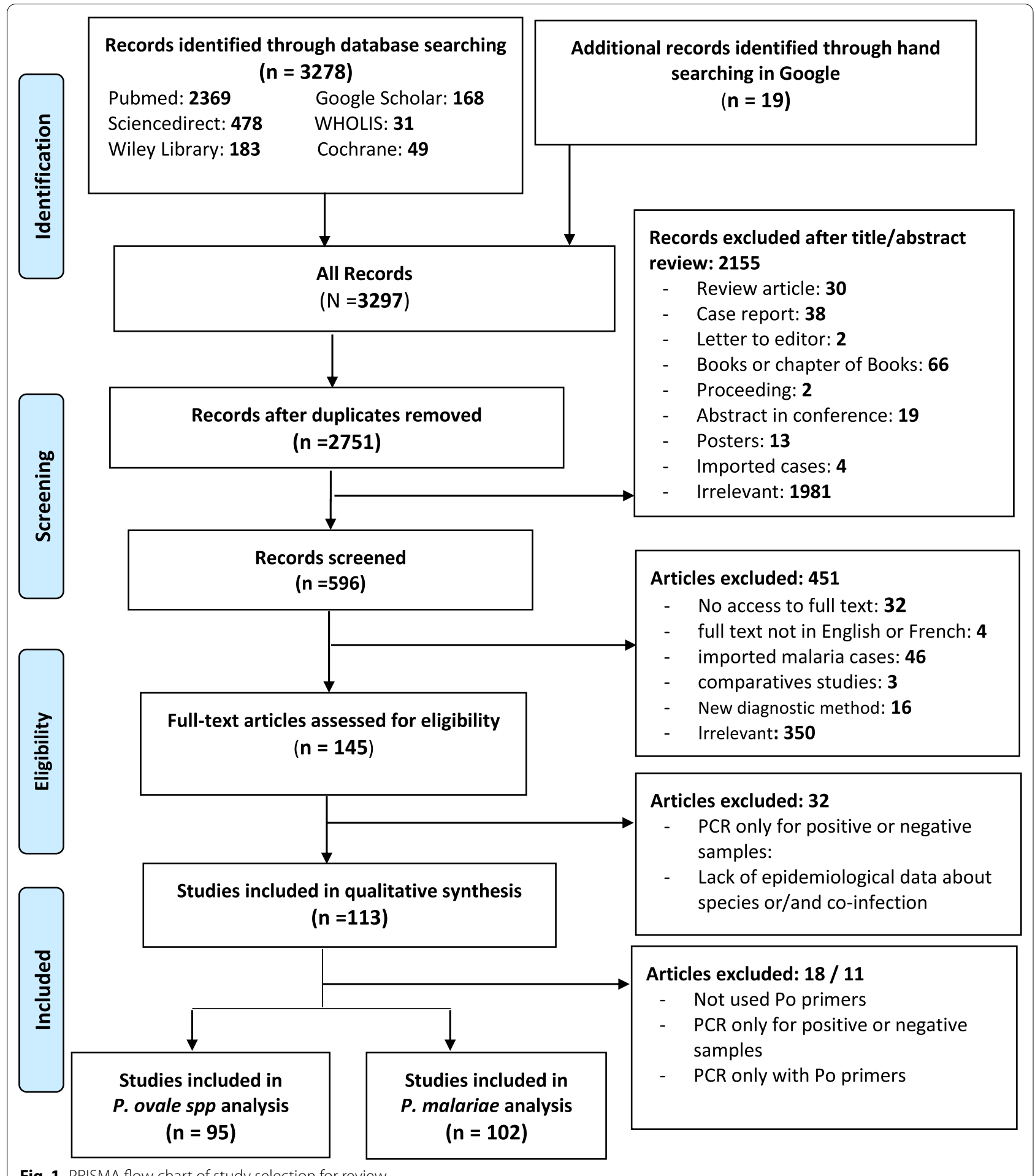

Fig. 1 PRISMA flow chart of study selection for review

spp. using the same model was found to be $0.77 \%$ (95\% CI $0.50-1.10 \%, \operatorname{tau}^{2}=0.02$ ), with significant heterogeneity $\left(I^{2}=97.85 \%, p<0.001\right)$ (Additional file 3: Tables S4 and S5).

\section{Subgroup analysis} Influence of WHO region

The AFR revealed the highest prevalence of the two 

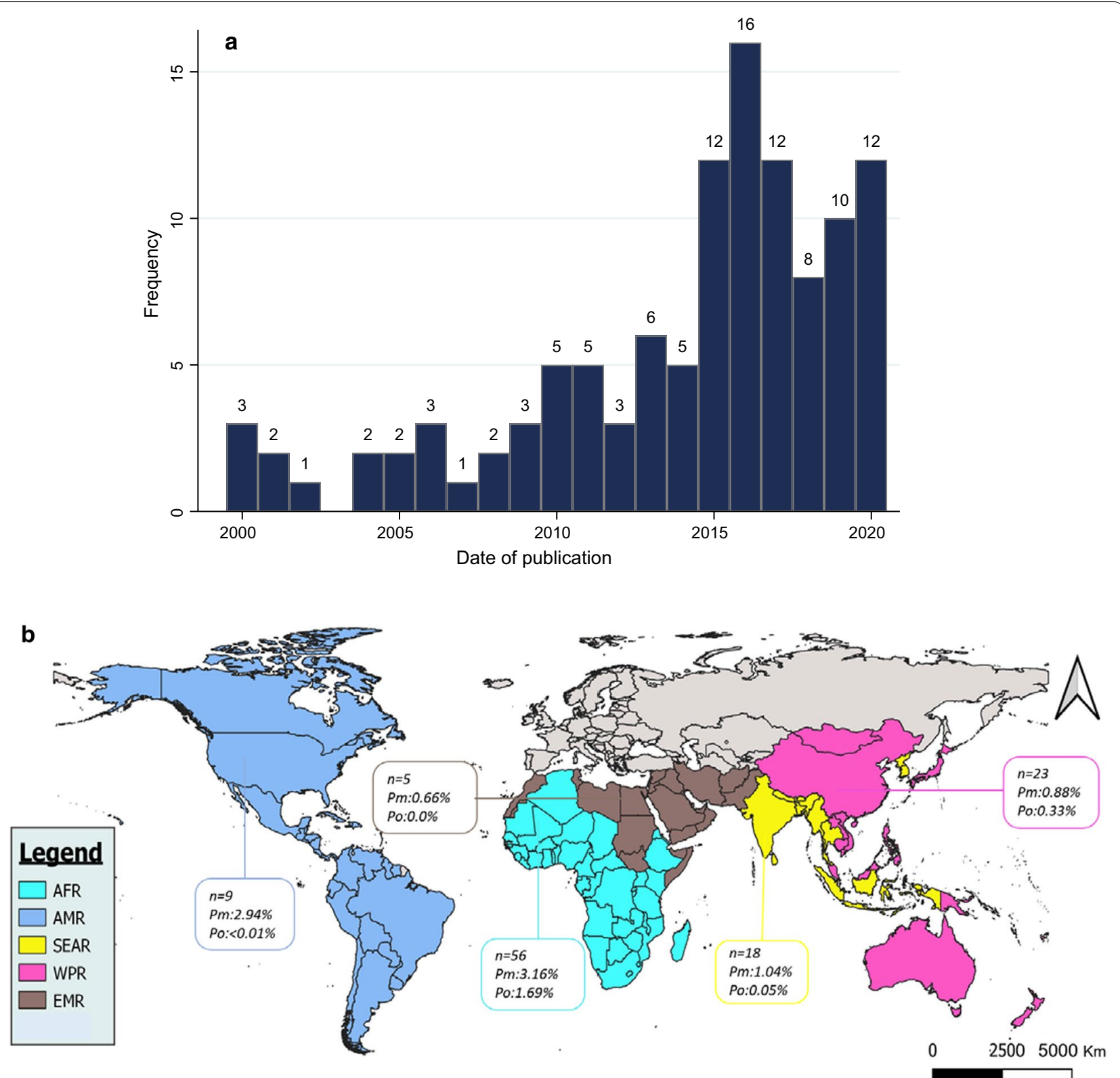

Fig. 2 a Distribution of included studies depending on the year. b Map of WHO regions where included studies were conducted. The regionalization used on this map is that of the WHO Global Health Observatory map. WHO Member States are grouped into six regions. The European region is not represented here, as it was not included in our study. (AFR: African Region, WPR: Western Pacific Region AMR: Region of the Americas, SEAR: South-East Asia Region, EMR: Eastern Mediterranean Region). n: number of included studies in each region. Pm: Plasmodium malariae, Po: Plasmodium ovale spp.

species studied, $3.16 \%$ (95\% CI 2.00-4.56\%) for $P$. malariae and $1.69 \%$ (95\% CI 1.11-2.38\%) for P. ovale spp. The EMR showed the lowest prevalence of $P$. malariae of $0.06 \%$ (95\% CI $0-0.52 \%$ ) and no cases of $P$. ovale spp. The AMR had the second highest $P$. malariae prevalence of $2.94 \%$ (95\% CI 0-12.56\%). The differences among regions were found to be statistically significant $\left(I^{2}=97.85 \%, p<0.001\right)($ Table 1$)$.

\section{Influence of participants' status: symptomatic versus asymptomatic}

The prevalence of $P$. malariae was found to be lower in asymptomatic than in symptomatic subjects, 1.31\% (95\% 
Table 1 Distribution of P. malariae and P. ovale spp. by WHO region

\begin{tabular}{|c|c|c|c|c|c|c|}
\hline \multirow[t]{2}{*}{ WHO region } & \multicolumn{3}{|l|}{ P. malariae } & \multicolumn{3}{|l|}{ P. ovale spp. } \\
\hline & No. of studies & Prevalence \% [95\% Cl] & $p$ value & No. of studies & Prevalence \% [95\% Cl] & $p$ value \\
\hline Africa & 50 & $3.16[2-4.56]$ & $<0.001$ & 50 & $1.69[1.11-2.38]$ & $<0.001$ \\
\hline Western Pacific & 21 & $0.88[0.24-1.87]$ & & 20 & $0.33[0.06-0.75]$ & \\
\hline South-East Asia & 17 & $1.04[0.33-2.08]$ & & 16 & $0.05[0.00-0.17]$ & \\
\hline Eastern Mediterranean & 5 & $0.06[0-0.52]$ & & 5 & No case & \\
\hline Americas & 9 & $2.94[0-12.56]$ & & 4 & $0.00[0-0.01]$ & \\
\hline
\end{tabular}

CI $0.60-1.71 \%)$ and $1.09 \%$ (95\% CI $0.04-3.92 \%)$, respectively, with no significant difference $(p=0.792)$ (Fig. 3a). Similarly, there was no significant difference $(p=0.107)$ for $P$. ovale spp. infection between symptomatic $0.60 \%$ (95\% CI $0.16-1.24 \%$ ) and asymptomatic subjects $0.22 \%$ (95\% CI 0.05-0.48\%) (Fig. 3b).

\section{Prevalence among children, adults and pregnant women}

On analysis, the P. malariae species was found to be equally distributed among adults $(2.13 \%$ with $95 \%$ CI $0.66-4.35 \%)$, children (2.90\% with $95 \%$ CI $0.94-5.84 \%)$ and pregnant women $(2.77 \%$ with $95 \%$ CI $0.72-6.01 \%)$ $(p=0.862)$. In contrast, the $P$ ovale spp. were seen to be more prevalent in pregnant women $2.90 \%$ (95\% CI $0.94-5.79 \%)$ than in children $\leq 15$ years $0.97 \%(95 \% \mathrm{CI}$ $0.08-2.66 \%)$ and in patients $>15$ years old $0.39 \%$ (95\% CI $0.10-0.85 \%)(p=0.021)$ (Figs. $4 \mathrm{a}, \mathrm{b})$.

\section{$P$. ovale wallikeri and $P$. ovale curtisi prevalence}

For $P$. ovale spp. pooled prevalence, only five out of 95 included studies clearly revealed $P$. ovale subspecies prevalence. In these studies, $P$. ovale curtisi $(1.65 \%$ with 95\% CI 0.14-4.73\%) appeared to be more prevalent than P. ovale wallikeri (1.55\% with $95 \%$ CI $0.38-3.47 \%)$. However, there was no significant difference between them $(p=0.698)$ (Additional file 4).

\section{Mixed infection prevalence}

The prevalence of $P$. malariae co-infections with at least one of the human Plasmodium species was $2.14 \%$ (95\% CI $1.32-3.15 \%$ ) versus $0.85 \%$ (95\% CI $0.59-1.16 \%$ ) in monoinfections, whereas $P$. ovale spp. showed a prevalence of $1.84 \%$ (95\% CI 1.16-2.69\%) in co-infections and $0.66 \%$ (95\% CI $0.43-0.94 \%$ ) in mono-infections. Analysis of the RD showed that both species were more likely to be present in co-infections than mono-infections in the studied subjects with RD value $4.16 \%$ (95\% CI 1.59-6.73\%, $p=0.002$ ) for P. malariae and 5.05\% (95\% CI 2.40-7.69\%, $p<0.001$ ) for P. ovale spp. (Additional file 5).

\section{Meta-regression and publication bias Evolution of prevalence over the years}

The evolution of $P$. malariae and $P$. ovale spp. prevalence over the years was explored by meta-regression. Globally, a negative correlation between pooled prevalence and years of data collection was observed, though it was not significant for either $P$. malariae $($ Coef $=-0.0131$; $p=0.059)$ or $P$. ovale spp. (Coef $=-0.0025 ; p=0.431)$ (Fig. 5a, b). This observation was also the same for each region separately except for the WPR, where the $P$. malariae prevalence had declined significantly $($ Coef $=-0.0212, p<0.001)$ (Additional file 6).

\section{Exploration of other potential confounders}

According to the results, none of the variables of sample size, year of publication or period of data collection was a significant moderator in estimation of either $P$. malariae or $P$. ovale spp. prevalence; therefore, no evidence of publication bias was observed in the estimated prevalence due to these factors (Table 2). In addition, the funnel plot does not indicate any evidence of publication bias for either of the two species. However, the exact Egger's test for small-study effect was significant for $P$. ovale spp. $(p=0.046)$, where the small study size may be the reason for bias towards $P$. ovale spp. prevalence (Additional file 7).

\section{Discussion}

In the past two decades, WHO has reported a slight decline in malaria cases, from 238 million cases in 2000 to 229 million in 2019, with incidence declining from 363 to 225 cases per 1000 population through increased coverage of preventive and control measures (particularly long-lasting insecticide-treated nets, early diagnosis using rapid diagnostic tests, global improvement of WHO's policy development and dissemination processes for malaria control) $[1,39,40]$. These have reflected in the regression of malaria and even its eradication in some countries during this period, notably in the United Arab Emirates, Morocco, Armenia, Argentina, Paraguay, Algeria, Uzbekistan, Sri Lanka, Turkmenistan and Kyrgyzstan [1]. This systematic review and meta-analysis estimated 


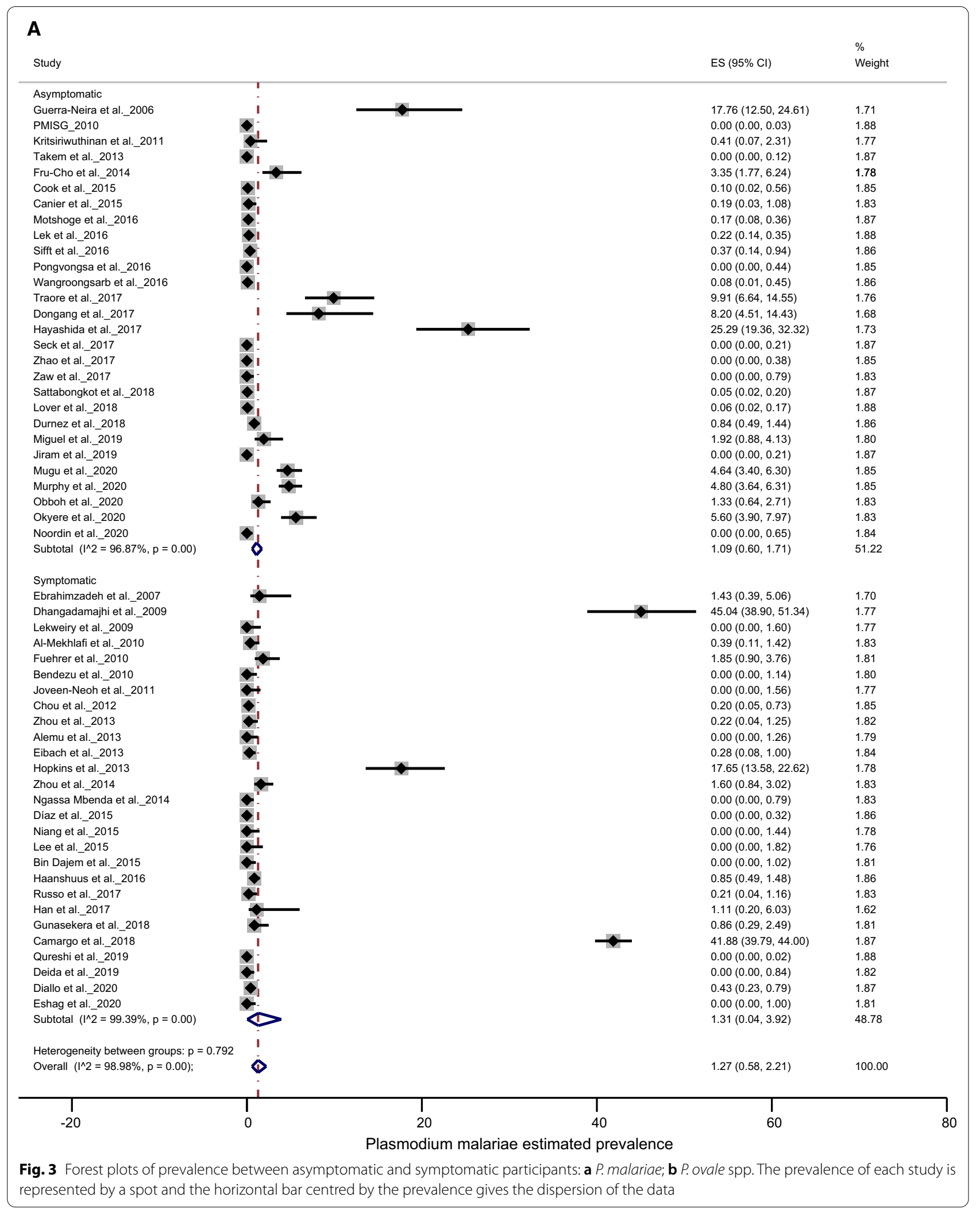




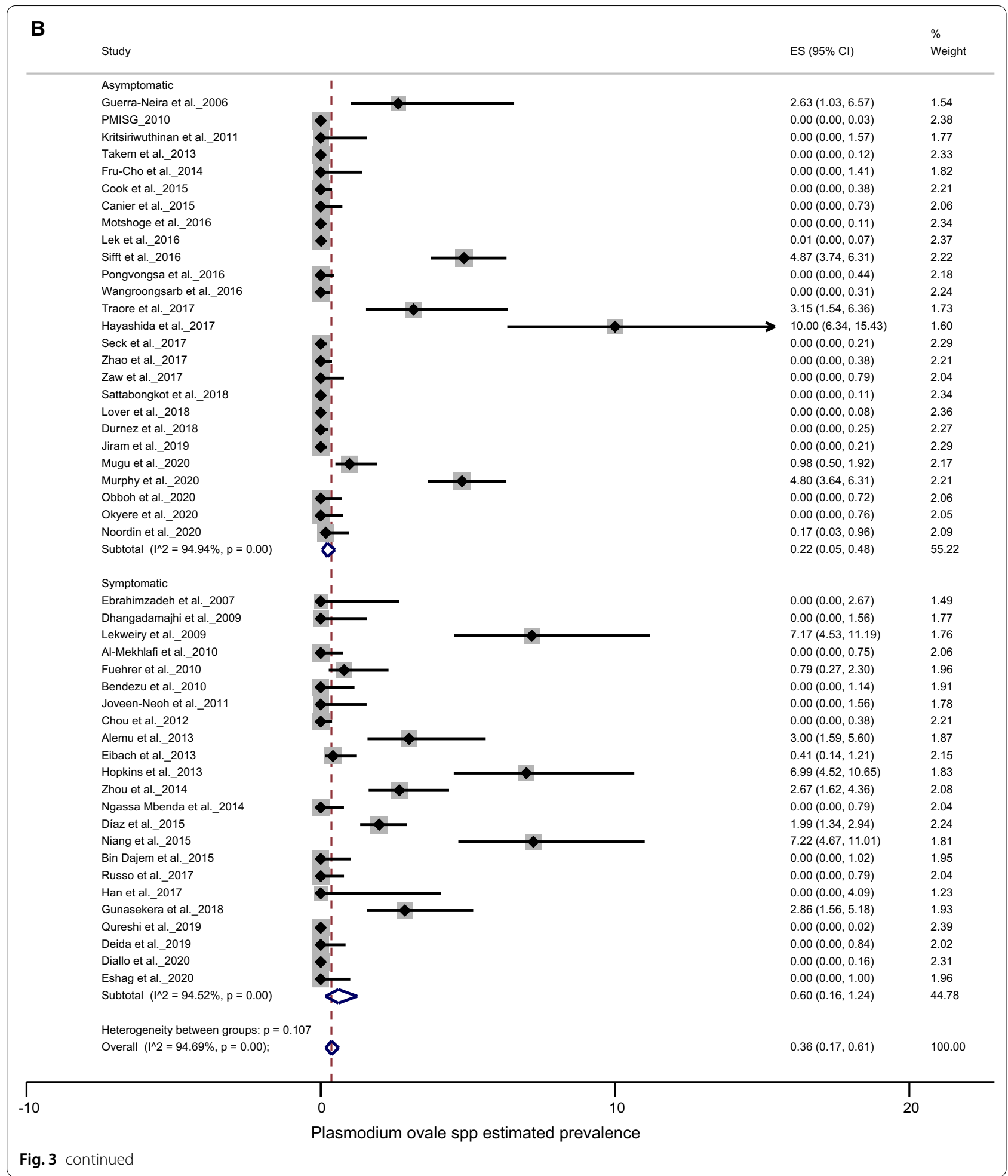

the disease trend of $P$. malariae and $P$. ovale spp. from January 2000 to December 2020.

The overall prevalence of $P$. malariae infections (2.01\%) was higher as compared to P. ovale spp. (0.77\%), with
AFR being the most frequently affected for both species. Epidemiological studies on malaria conducted in the AMR, SEAR and EMR did not very often pay attention to $P$. malariae and/or P. ovale spp. due to their low 


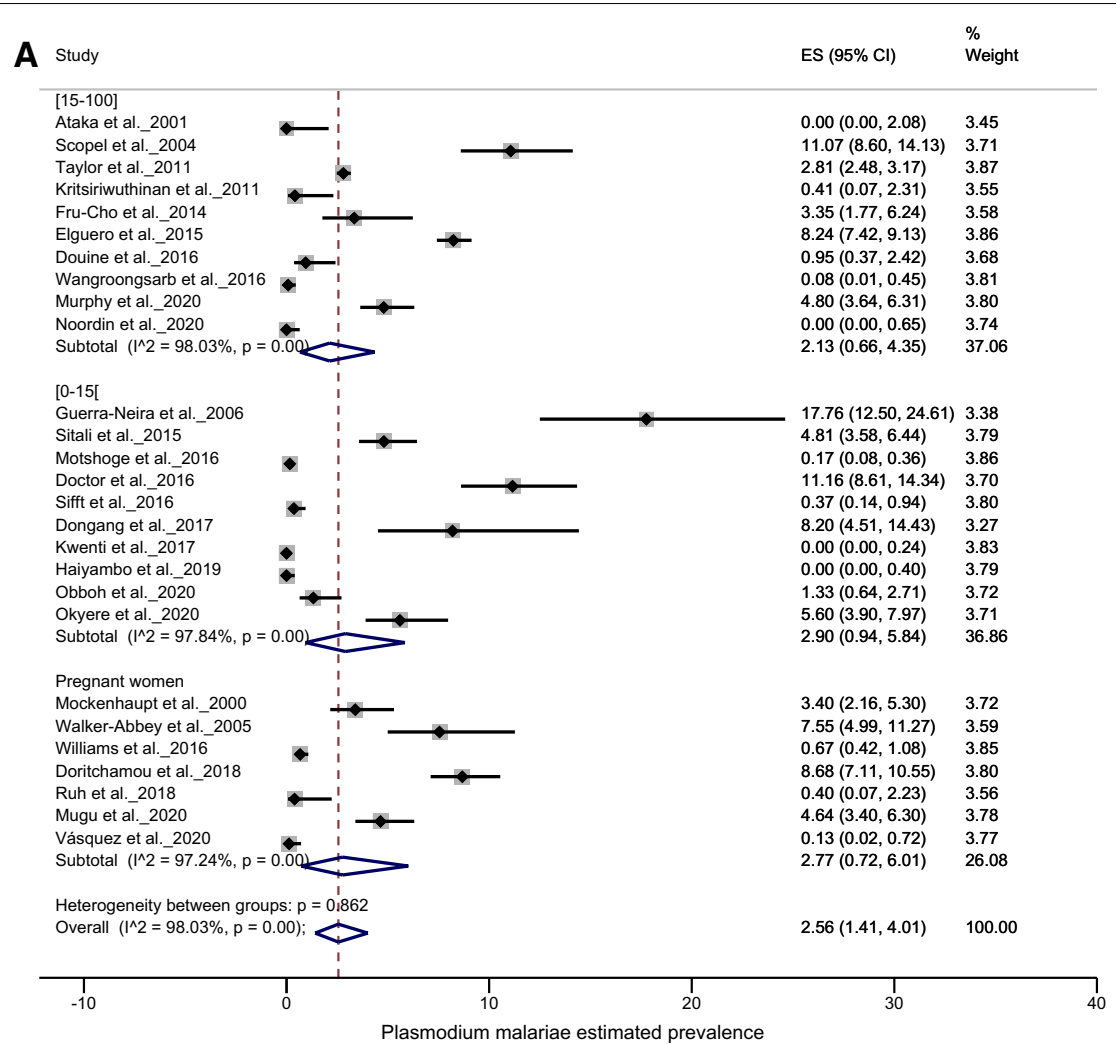

B study

ES $(95 \% \mathrm{Cl}) \quad \stackrel{\%}{\text { Weight }}$

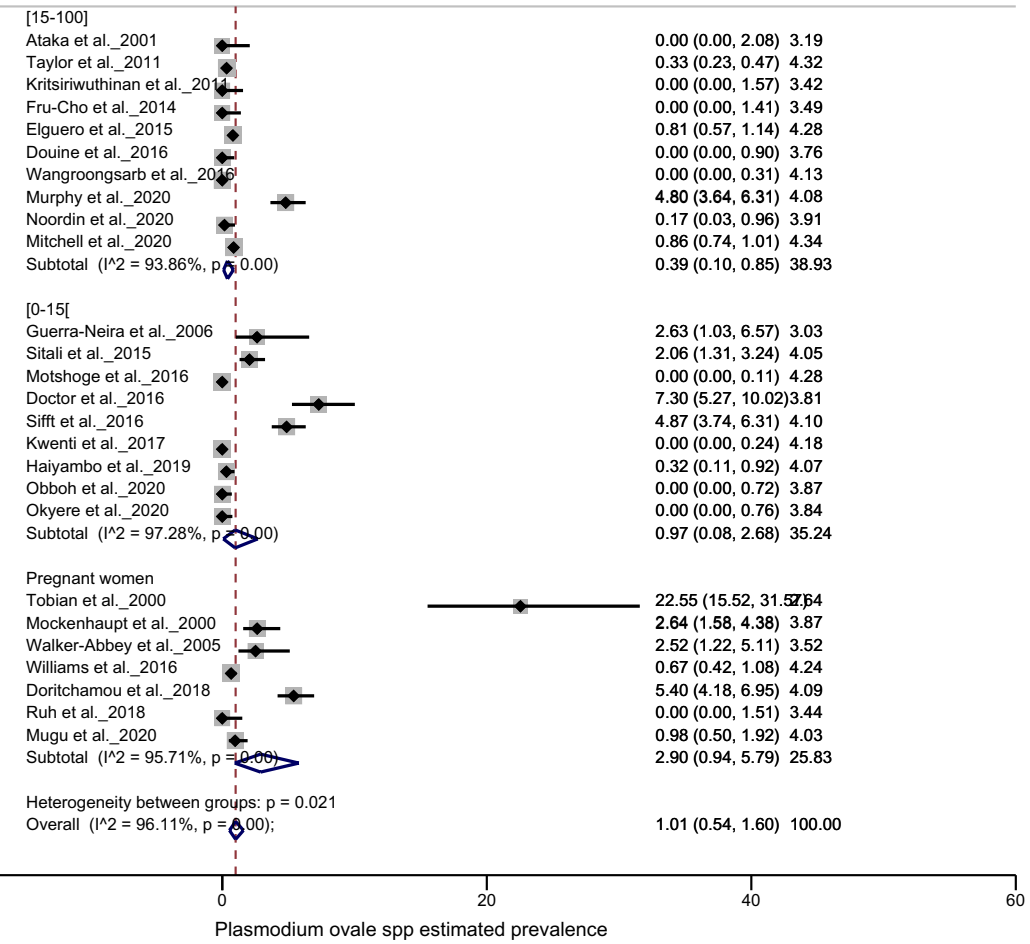

Fig. 4 Forest plots of Plasmodium prevalence in studies conducted in specific groups (pregnant women, children under 15 and participants over 15 years old). a $P$. malariae prevalence, $\mathbf{b}$ P. ovale spp. prevalence. The prevalence of each study is represented by a spot and the horizontal bar centred by the prevalence gives the dispersion of the data 

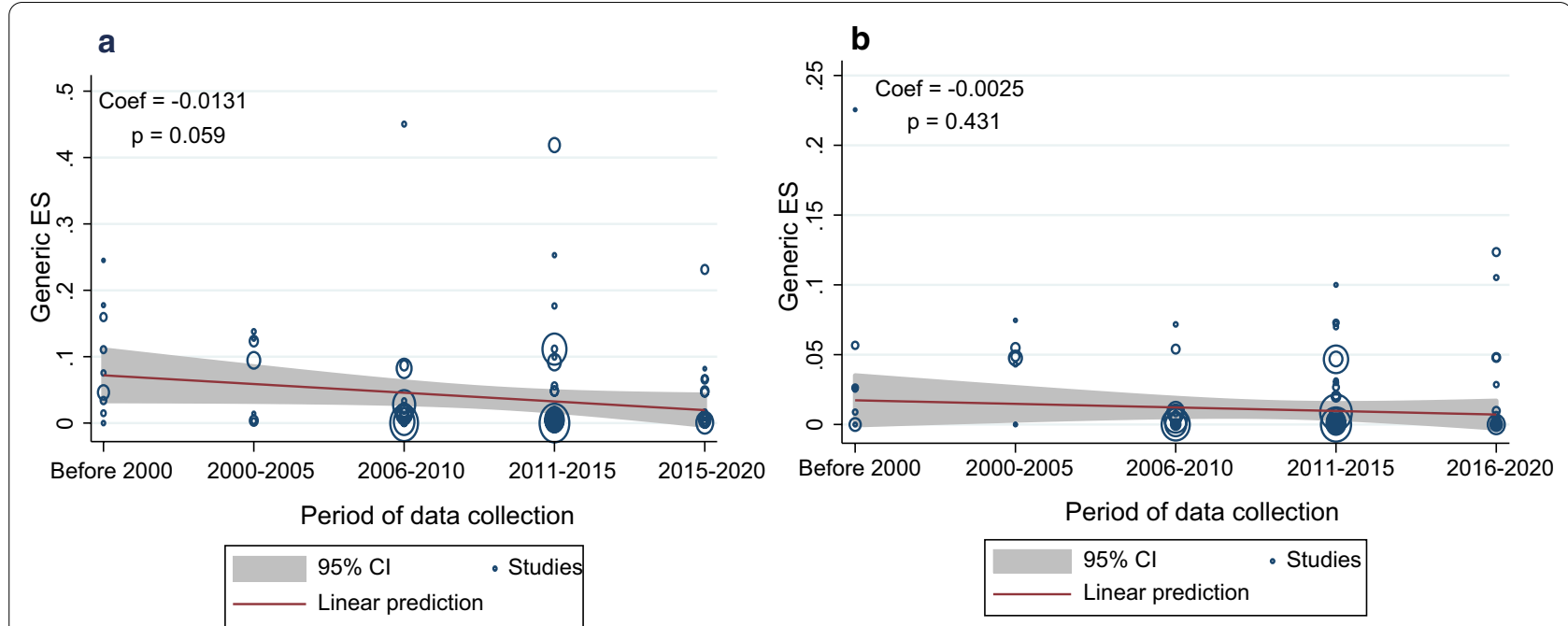

Fig. 5 Meta-regression of prevalence over the period of data collection: a meta-regression of P. malariae prevalence, $\mathbf{b}$ meta-regression of $P$. ovale spp. prevalence

Table 2 Meta-regression of potential confounders: sample size, date of publication, period of data collection

\begin{tabular}{|c|c|c|c|c|c|c|}
\hline \multirow{2}{*}{$\begin{array}{l}\text { Species } \\
\text { P. malariae }\end{array}$} & \multirow{2}{*}{$\begin{array}{l}\text { Cofactors } \\
\text { Sample size }\end{array}$} & \multirow{2}{*}{$\begin{array}{l}\text { Coef } \\
-2.36 \mathrm{E}-06\end{array}$} & \multicolumn{2}{|c|}{ [95\% confidence interval] } & \multirow{2}{*}{$\frac{z}{-0.95}$} & \multirow{2}{*}{$\begin{array}{l}p \text { value } \\
0.342\end{array}$} \\
\hline & & & $-7.24 E-06$ & $2.51 \mathrm{E}-06$ & & \\
\hline & Date of publication & -0.0021299 & -0.0051524 & 0.0008927 & -1.38 & 0.167 \\
\hline & Period of data collection & -0.0131058 & -0.0266983 & 0.0004866 & -1.89 & 0.059 \\
\hline \multirow[t]{3}{*}{ P. ovale spp. } & Sample size & $-4.95 E-07$ & $-1.44 \mathrm{E}-06$ & $4.45 \mathrm{E}-07$ & -1.03 & 0.302 \\
\hline & Date of publication & -0.0003042 & -0.0015801 & 0.0009716 & -0.47 & 0.640 \\
\hline & Period of data collection & -0.0025502 & -0.008897 & 0.0037966 & -0.79 & 0.431 \\
\hline
\end{tabular}

prevalence/severity [12, 41-46], yet some studies report P. malariae prevalence of more than $40 \%$ in these regions $[12,47]$. This may be the reason for the underestimation of $P$. malariae and $P$. ovale spp. prevalence rates in these regions, as observed in this review. Negative correlations obtained in the meta-regression of prevalence as a function of data collection period indicate that the prevalence of both $P$. malariae and $P$. ovale spp. species have declined over the last 20 years, but not significantly. WHO has several strategic programmes to eliminate malaria, with a particular focus on P. falciparum and $P$. vivax malaria but none specific to $P$. malariae or $P$. ovale spp., which may have resulted in a low regression observed for these two species with a significant decline of $P$. falciparum and $P$. vivax prevalence recorded globally $[39,48]$.

Gneme et al. [49], in a 4-year longitudinal study conducted in Burkina Faso from 2007 to 2010, revealed that the prevalence of $P$. malariae increased 15 -fold and that of $P$. ovale spp. increased fourfold. Moreover, in the last 5 years, fairly high prevalence has been reported for $P$. ovale spp. $[10,13]$ and $P$. malariae $[9,10,12](>10 \%$ and
$20 \%$, respectively) in AFR and AMR due to the increased usage of diagnostic PCR assay [50]. The P. ovale spp. was reported in 12 out of 26 provinces of the DRC during 2007. Six years later, in 2013, the demographic and health survey revealed $P$. ovale spp. in $24 / 26$ provinces of DRC, with an increased prevalence in several provinces [51]. This reflects a spread of $P$. ovale spp. that urgently needs to be addressed, as DRC is the second most affected country by malaria in the world [1]. Several studies have also reported an equal distribution of $P$. ovale subspecies in AFR [21, 32, 35, 51]. High prevalence of asymptomatic malaria including $P$. malariae $[9,34,42,52-54]$ and $P$. ovale spp. $[9,35,54,55]$ infections were reported in many studies. Our analysis indicates that both species showed the same distribution between symptomatic and asymptomatic subjects [56]. P. malaria and $P$. ovale spp. are often misidentified as $P$. falciparum and $P$. vivax, respectively, which complicates the routine diagnosis $[8,57]$ and further leads to asymptomatic disease reservoirs [36] which could jeopardize malaria elimination programmes and therefore merits more attention. 
Children and pregnant women are well known as vulnerable groups to malaria infection. Woldearegai et al. [10] reported in a Gabonese population that immunity to $P$. malariae builds up with age similarly to $P$. falciparum, but incompletely due to lower parasitaemia, which induces limited immune stimulation. In this study, subgroup analysis showed that $P$. malariae appears to have the same distribution in children, adults and pregnant women, whereas the highest $P$. ovale spp. prevalence among the subgroups was observed in pregnant women. Knowing that $P$. malariae has the same therapeutic protocol as $P$. falciparum $[3,58]$, the use of intermittent preventive treatment in pregnancy (ITPp) contributes to the reduction of $P$. malariae burden in this group, unlike $P$. ovale spp., which can remain dormant in the liver (hypnozoites stage) for long periods. A cross-sectional study including 4570 women of childbearing age conducted by Taylor et al. [26] found that $P$. malariae was more prevalent in non-pregnant than pregnant women in the Wocba region (DRC). Unfortunately, this observation could not be linked with any factor, as the authors had no data on ITPp or antenatal care. On the other hand, Mitchell and colleagues reported $P$. ovale spp. prevalence twice as high in men (mainly miners) as in women, suggesting that male susceptibility was possibly due to the high exposure in their work environment. Therefore, the conclusions as to the risk groups for these two species remain controversial.

In the reported meta-analysis, the difference in risk of co-infections with another Plasmodium species reveals that both $P$. malariae and $P$. ovale spp. occurred more in co-infections, as reported earlier [9, 10, 13, 59-62]. The recurrence of the coexistence of two or more Plasmodium species can be explained by the densitydependent regulation model proposed by Bruce and Day $[63,64]$. This model suggests that when an individual carrying a Plasmodium species is reinfected by a second species, the parasitaemia due to the first species is down-regulated. However, when the species with the highest parasitaemia exceeds a certain threshold, the host immune response is triggered to control the infection. Once the infection is under control, the system is deactivated, promoting the growth of the second infecting species. This cycle is believed to be responsible for the persistence of several species in the host. In addition, it is also known that $P$. malariae and $P$. ovale spp. preferentially develop in mature and younger red blood cells respectively $[65,66]$. This differential target of invasion and no antagonism mechanism reported between these two species could explain their co-existence in an individual. Obviously, this requires further research, as not much data is available in this regard. Although not considered a significant threat to malaria elimination, the insufficient knowledge of the biological dynamics of $P$. malariae and $P$. ovale spp. should not be neglected because of their low prevalence and disease severity.

The strength of this study lies in the estimation of the prevalence rates of these two non-falciparum species based essentially on molecular techniques known to be the most sensitive diagnostic tool, and the global coverage of the WHO health regions in the last two decades, thus offering a global overview of $P$. malariae and $P$. ovale spp. malaria burden. However, the lack of whole information in some studies made it impossible to thoroughly analyse the data for identifying the environmental and biological factors that regulate the dynamics of these two species and which will be the subject of our future investigations.

\section{Limitations}

However, this study had certain limitations. First, the pooled prevalence data was estimated from studies conducted in different geographic areas and at different times, as reflected in the high heterogeneity observed. Second, the AFR had ten times as many papers as some of the regions included, which could be a source of imbalance in pooled prevalence data. Third, not all studies mentioned the characteristics of the study areas to permit us to explore other sources of heterogeneity. Fourth, only papers published in English or French were included in this review. Finally, field or laboratory working conditions that were not always clearly detailed and/ or sometimes differed could have generated several other confounding variables that affected our results.

\section{Conclusion}

This study summarizes the distribution and the global trend of $P$. malariae and $P$. ovale spp. prevalence in the last two decades. Based on our results, the prevalence of both species has declined slightly over this period, although high prevalence has been recorded in AFR and the AMR recently. Both species are equally prevalent in asymptomatic and symptomatic individuals of all age groups, which supports the interest of their inclusion in the new strategies for prevention, treatment and malaria elimination programmes.

\section{Abbreviations}

AFR: African Region; AMR: Region of the Americas; DRC: Democratic Republic of the Congo; EMR: Eastern Mediterranean Region; JBI: Joanna Briggs Institute; LAMP: Loop-mediated isothermal amplification; PCR: Polymerase chain

reaction; PRISMA: Preferred Reporting Items for Systematic Reviews and MetaAnalyses; GPCR: Quantitative polymerase chain reaction; RD: Risk difference; 
RT-PCR: Real-time polymerase chain reaction; SEAR: South-East Asia Region; WPR: Western Pacific Region.

\section{Supplementary Information}

The online version contains supplementary material available at https://doi. org/10.1186/s13071-021-04797-0.

Additional file 1. PRISMA Checklist.

Additional file 2. Search strategy.

Additional file 3. Table S1. Score of included study. Table S2. Studies excluded from meta-analysis. Table $\mathbf{S 3}$. Characteristics of included studies. Table S4. Plasmodium malariae pooled prevalence. Table S5. Plasmodium ovale in future. pooled prevalence.

Additional file 4. Comparison of P. ovale curtisi and P. ovale wallikeri prevalence.

Additional file 5. Risk difference (RD) mono-infection vs mix infection.

Additional file 6. Meta-regression of prevalence over the period of data collection by region.

Additional file 7. Funnel plot for publication bias and Egger's test for small study effects.

\section{Acknowledgements}

The authors are grateful to the Department of Biotechnology (DBT), Government of India and The World Academy of Sciences (TWAS) for awarding Fellowship to JH and RRDN at the ICMR-National Institute of Malaria Research, Delhi, India. The authors also thank Stéphane Koum, Ph.D. (University of Douala, Cameroon) for compiling the map.

\section{Authors' contributions}

All authors have contributed to the study design. VS designed the study. JH and RRDN conducted the literature search, extracted and analysed the data. $J H$ and RRDN wrote the manuscript and VS reviewed it. VS supervised all stages of the work. All authors read and approved the final manuscript.

\section{Funding}

This research did not receive any specific grant from funding agencies in the public, commercial, or not-for-profit sectors.

\section{Availability of data and materials}

All data generated or analyzed during this study are included in this published article and its additional files.

\section{Declarations}

\section{Ethical considerations}

As this is a systematic review and meta-analysis, ethical approval was not required. However, the recommendations in the PRISMA guidelines were strictly followed in conducting this systematic review and meta-analysis.

\section{Consent for publication}

Not applicable.

\section{Competing interests}

The authors declare that they have no conflicts of interest.

\section{Author details}

'ICMR-National Institute of Malaria Research, Dwarka, Sector 8, New-Delhi 110077, India. ${ }^{2}$ Institute of Medical Research and Medicinal Plants Studies, PO Box 13033, Yaoundé, Cameroon.

Received: 25 February 2021 Accepted: 20 May 2021

Published online: 03 June 2021

\section{References}

1. WHO. World malaria report 2020. Geneva: World Health Organization; 2020.

2. Imwong M, Hien TT, Thuy-Nhien NT, Dondorp AM, White NJ. Spread of a single multidrug resistant malaria parasite lineage (PfPailin) to Vietnam. Lancet Infect Dis. 2017;17:1022-3.

3. Su X, Lane KD, Xia L, Sá JM, Wellems TE. Plasmodium genomics and genetics: new insights into malaria pathogenesis, drug resistance, epidemiology, and evolution. Clin Microbiol Rev. 2019:32:e00019-19.

4. Nsanzabana C. Resistance to Artemisinin Combination Therapies (ACTs): do not forget the partner drug! Trop Med Infect Dis. 2019;4:26.

5. Amoah LE, Donu D, Abuaku B, Ahorlu C, Arhinful D, Afari E, et al. Probing the composition of Plasmodium species contained in malaria infections in the eastern region of Ghana. BMC Public Health. 2019;19:1617.

6. Yman V, Wandell G, Mutemi DD, Miglar A, Asghar M, Hammar U, et al. Persistent transmission of Plasmodium malariae and Plasmodium ovale species in an area of declining Plasmodium falciparum transmission in eastern Tanzania. PLoS Negl Trop Dis. 2019;13:e0007414.

7. Rajahram GS, Cooper DJ, William T, Grigg MJ, Anstey NM, Barber BE. Deaths from Plasmodium knowlesi malaria: case series and systematic review. Clin Infect Dis. 2019;69:1703-11.

8. Kotepui M, Kotepui KU, Milanez GD, Masangkay FR. Severity and mortality of severe Plasmodium ovale infection: a systematic review and metaanalysis. PLoS ONE. 2020;15:e0235014.

9. Hayashida K, Kajino K, Simukoko H, Simuunza M, Ndebe J, Chota A, et al. Direct detection of falciparum and non-falciparum malaria DNA from a drop of blood with high sensitivity by the dried-LAMP system. Parasit Vectors. 2017;10:26.

10. Woldearegai TG, Lalremruata A, Nguyen TT, Gmeiner M, Veletzky L, Tazemda-Kuitsouc GB, et al. Characterization of Plasmodium infections among inhabitants of rural areas in Gabon. Sci Rep. 2019;9:9784.

11. Taylor SM, Messina JP, Hand CC, Juliano JJ, Muwonga J, Tshefu AK, et al. Molecular malaria epidemiology: mapping and burden estimates for the Democratic Republic of the Congo, 2007. PLoS ONE. 2011;6:e16420.

12. Camargo M, Soto-De León SC, Del Río-Ospina L, Páez AC, González Z, González E, et al. Micro-epidemiology of mixed-species malaria infections in a rural population living in the Colombian Amazon region. Sci Rep. 2018;8:5543.

13. Sitali L, Miller JM, Mwenda MC, Bridges DJ, Hawela MB, Hamainza B, et al. Distribution of Plasmodium species and assessment of performance of diagnostic tools used during a malaria survey in southern and western provinces of Zambia. Malar J. 2019;18:130.

14. Guerra Rl, Ore M, Valdivia HO, Bishop DK, Ramos M, Mores CN, et al. A cluster of the first reported Plasmodium ovale spp. infections in Peru occuring among returning UN peace-keepers, a review of epidemiology, prevention and diagnostic challenges in nonendemic regions. Malar J. 2019;18:176.

15. Moher D, Liberati A, Tetzlaff J, Altman DG, The PRISMA Group. Preferred reporting items for systematic reviews and meta-analyses: the PRISMA statement. PLoS Med. 2009;6:e1000097.

16. Munn Z, Moola S, Lisy K, Riitano D, Tufanaru C. Methodological guidance for systematic reviews of observational epidemiological studies reporting prevalence and cumulative incidence data. Int J Evid Based Healthc. 2015;13:147-53.

17. Nyaga VN, Arbyn M, Aerts M. Metaprop: a Stata command to perform meta-analysis of binomial data. Arch Public Health. 2014;72:39.

18. Tobian AA, Mehlotra RK, Malhotra I, Wamachi A, Mungai P, Koech D, et al. Frequent umbilical cord-blood and maternal-blood infections with Plasmodium falciparum, P. malariae, and P. ovale in Kenya. J Infect Dis. 2000;182:558-63.

19. Mockenhaupt FP, Rong B, Till H, Eggelte TA, Beck S, Gyasi-Sarpong C, et al. Submicroscopic Plasmodium falciparum infections in pregnancy in Ghana. Trop Med Int Health. 2000;5:167-73.

20. Walker-Abbey A, Djokam RRT, Eno A, Leke RFG, Titanji VPK, Fogako J, et al. Malaria in pregnant Cameroonian women: the effect of age and gravidity on submicroscopic and mixed-species infections and multiple parasite genotypes. Am J Trop Med Hyg. 2005;72:229-35.

21. Williams J, Njie F, Cairns M, Bojang K, Coulibaly SO, Kayentao K, et al. Non-falciparum malaria infections in pregnant women in west Africa. Malar J. 2016;15:53. 
22. Ruh E, Bateko JP, Imir T, Taylan-Ozkan A. Investigation of pregnancyassociated malaria by microscopy, rapid diagnostic test and PCR in Bandundu, the Democratic Republic of Congo. Trans R Soc Trop Med Hyg. 2018;112:8-13.

23. Doritchamou JYA, Akuffo RA, Moussiliou A, Luty AJF, Massougbodji A, Deloron $P$, et al. Submicroscopic placental infection by non-falciparum Plasmodium spp. PLoS Negl Trop Dis. 2018;12:e0006279.

24. Kalinjuma AV, Darling AM, Mugusi FM, Abioye Al, Okumu FO, Aboud S, et al. Factors associated with sub-microscopic placental malaria and its association with adverse pregnancy outcomes among HIV-negative women in Dar es Salaam, Tanzania: a cohort study. BMC Infect Dis. 2020;20:796.

25. Vásquez A-M, Zuluaga-Idárraga L, Arboleda M, Usuga L-Y, GallegoMarin C, Lasso A, et al. Malaria in pregnancy in endemic regions of Colombia: high frequency of asymptomatic and peri-urban infections in pregnant women with malaria. Infect Dis Obstet Gynecol. 2020;2020:2750258.

26. Taylor SM, van Eijk AM, Hand CC, Mwandagalirwa K, Messina JP, Tshefu AK, et al. Quantification of the burden and consequences of pregnancy-associated malaria in the Democratic Republic of the Congo. J Infect Dis. 2011;204:1762-71.

27. Lee K-S, Cox-Singh J, Singh B. Morphological features and differential counts of Plasmodium knowlesi parasites in naturally acquired human infections. Malar J. 2009:8:73.

28. Joveen-Neoh WF, Chong KL, Wong CMVL, Lau TY. Incidence of malaria in the interior division of Sabah, Malaysian Borneo, based on nested PCR. J Parasitol Res. 2011;2011:104284.

29. Lee PC, Chong ETJ, Anderios F, Al Lim Y, Chew CH, Chua KH. Molecular detection of human Plasmodium species in Sabah using PlasmoNex ${ }^{\text {TM }}$ multiplex PCR and hydrolysis probes real-time PCR. Malar J. 2015;14:28.

30. Ghinai I, Cook J, Hla TTW, Htet HMT, Hall T, Lubis IN, et al. Malaria epidemiology in central Myanmar: identification of a multi-species asymptomatic reservoir of infection. Malar J. 2017;16:16.

31. Jiram Al, Ooi CH, Rubio JM, Hisam S, Karnan G, Sukor NM, et al. Evidence of asymptomatic submicroscopic malaria in low transmission areas in Belaga district, Kapit division, Sarawak. Malaysia Malar J. 2019;18:156.

32. Fançony C, Gamboa D, Sebastião Y, Hallett R, Sutherland C, Sousa-Figueiredo JC, et al. Various pfcrt and pfmdr1 genotypes of Plasmodium falciparum cocirculate with $P$. malariae, $P$. ovale spp., and $P$. vivax in northern Angola. Antimicrob Agents Chemother. 2012;56:5271-7.

33. Daniels RF, Deme AB, Gomis JF, Dieye B, Durfee K, Thwing Jl, et al. Evidence of non-Plasmodium falciparum malaria infection in Kédougou. Sénégal Malar J. 2017;16:9.

34. Heinemann M, Phillips RO, Vinnemeier CD, Rolling CC, Tannich E, Rolling T. High prevalence of asymptomatic malaria infections in adults, Ashanti Region, Ghana, 2018. Malar J. 2020;19:366.

35. Murphy KJ, Conroy AL, Ddungu H, Shrestha R, Kyeyune-Byabazaire D, Petersen MR, et al. Malaria parasitemia among blood donors in Uganda. Transfusion. 2020;60:955-64.

36. Noordin NR, Lee PY, Mohd Bukhari FD, Fong MY, Abdul Hamid MH, Jelip $J$, et al. Prevalence of asymptomatic and/or low-density malaria infection among high-risk groups in Peninsular Malaysia. Am J Trop Med Hyg. 2020;103:1107-10.

37. Oriero EC, Olukosi AY, Oduwole OA, Djimde A, D'Alessandro U, Meremikwu MM, et al. Seroprevalence and parasite rates of Plasmodium malariae in a high malaria transmission setting of southern Nigeria. Am J Trop Med Hyg. 2020;103:2208-16.

38. Putaporntip C, Buppan P, Jongwutiwes S. Improved performance with saliva and urine as alternative DNA sources for malaria diagnosis by mitochondrial DNA-based PCR assays. Clin Microbiol Infect. 2011;17:1484-91.

39. WHO. Global technical strategy for malaria 2016-2030. Geneva: World Health Organization; 2015.

40. Bhatt S, Weiss DJ, Mappin B, Dalrymple U, Cameron E, Bisanzio D, et al Coverage and system efficiencies of insecticide-treated nets in Africa from 2000 to 2017. Elife. 2015;4:e09672.

41. Zhou X, Li S-G, Chen S-B, Wang J-Z, Xu B, Zhou H-J, et al. Co-infections with Babesia microti and Plasmodium parasites along the China-Myanmar border. Infect Dis Poverty. 2013;2:24.

42. Scopel KKG, Fontes CJF, Nunes AC, Horta MF, Braga EM. High prevalence of Plamodium malariae infections in a Brazilian Amazon endemic area
(Apiacás-Mato Grosso State) as detected by polymerase chain reaction. Acta Trop. 2004;90:61-4.

43. Curado I, Dos Santos MR, de Castro Duarte AMR, Kirchgatter K, Branquinho MS, Bianchi Galati EA. Malaria epidemiology in low-endemicity areas of the atlantic forest in the Vale do Ribeira, São Paulo. Brazil Acta Trop. 2006;100:54-62.

44. Cucunubá ZM, Guerra AP, Rahirant SJ, Rivera JA, Cortés LJ, Nicholls RS. Asymptomatic Plasmodium spp. infection in Tierralta. Colombia Mem Inst Oswaldo Cruz. 2008;103:668-73.

45. Haanshuus CG, Chandy S, Manoharan A, Vivek R, Mathai D, Xena D, et al. A high malaria prevalence identified by PCR among patients with acute undifferentiated fever in India. PLOS ONE. 2018:13:e0193574.

46. Miguel RB, Albuquerque HG, Sanchez MCA, Coura JR, da Santos SS, da Silva $\mathrm{S}$, et al. Asymptomatic Plasmodium infection in a residual malaria transmission area in the atlantic forest region: implications for elimination. Rev Soc Bras Med Trop. 2019;52:e20180537.

47. Dhangadamajhi G, Kar SK, Ranjit MR. High prevalence and gender bias in distribution of Plasmodium malariae infection in central east-coast India. Trop Biomed. 2009;26:326-33.

48. Weiss DJ, Lucas TCD, Nguyen M, Nandi AK, Bisanzio D, Battle KE, et al. Mapping the global prevalence, incidence, and mortality of Plasmodium falciparum, 2000-17: a spatial and temporal modelling study. Lancet. 2019;394:322-31.

49. Gnémé A, Guelbéogo WM, Riehle MM, Tiono AB, Diarra A, Kabré GB, et al. Plasmodium species occurrence, temporal distribution and interaction in a child-aged population in rural Burkina Faso. Malar J. 2013;12:67.

50. WHO. World malaria report 2017. Geneva: World Health Organization; 2017

51. Mitchell CL, Brazeau NF, Keeler C, Mwandagalirwa MK, Tshefu AK, Juliano $J$, et al. Under the radar: epidemiology of Plasmodium ovale in the Democratic Republic of the Congo. J Infect Dis. 2021;223:1005-14.

52. Guerra-Neira A, Rubio JM, Royo JR, Ortega JC, Auñón AS, Diaz PB, et al. Plasmodium diversity in non-malaria individuals from the Bioko Island in Equatorial Guinea (West Central-Africa). Int J Health Geogr. 2006;5:27.

53. Roman DNR, Rosalie NNA, Kumar A, Luther KMM, Singh V, Albert MS. Asymptomatic Plasmodium malariae infections in children from suburban areas of Yaoundé. Cameroon Parasitol Int. 2018;67:29-33.

54. Traore K, Thera MA, Bienvenu A-L, Arama C, Bonnot G, Lavoignat A, et al. Interaction between environment, nutrient-derived metabolites and immunity: a possible role in malaria susceptibility/resistance in Fulani and Dogon of Mali. PLoS ONE. 2017;12:e0189724.

55. Sifft KC, Geus D, Mukampunga C, Mugisha JC, Habarugira F, Fraundorfer $K$, et al. Asymptomatic only at first sight: malaria infection among schoolchildren in highland Rwanda. Malar J. 2016;15:553.

56. Doolan DL, Dobaño C, Baird JK. Acquired immunity to malaria. Clin Microbiol Rev. 2009;22:13-36

57. Kotepui M, Kotepui KU, Milanez GD, Masangkay FR. Global prevalence and mortality of severe Plasmodium malariae infection: a systematic review and meta-analysis. Malar J. 2020;19:1-13.

58. Kajubi R, Ochieng T, Kakuru A, Jagannathan P, Nakalembe M, Ruel T, et al. Monthly sulfadoxine-pyrimethamine versus dihydroartemisinin-piperaquine for intermittent preventive treatment of malaria in pregnancy: a double-blind, randomised, controlled, superiority trial. Lancet. 2019;393:1428-39.

59. Hopkins H, González IJ, Polley SD, Angutoko P, Ategeka J, Asiimwe C, et al. Highly sensitive detection of malaria parasitemia in a malaria-endemic setting: performance of a new loop-mediated isothermal amplification kit in a remote clinic in Uganda. J Infect Dis. 2013;208:645-52.

60. Niang M, Thiam LG, Sow A, Loucoubar C, Bob NS, Diop F, et al. A molecular survey of acute febrile illnesses reveals Plasmodium vivax infections in Kedougou, southeastern Senegal. Malar J. 2015;14:281.

61. Doctor SM, Liu Y, Anderson OG, Whitesell AN, Mwandagalirwa MK, Muwonga J, et al. Low prevalence of Plasmodium malariae and Plasmodium ovale mono-infections among children in the Democratic Republic of the Congo: a population-based, cross-sectional study. Malar J. 2016;15:350.

62. Steenkeste N, Rogers WO, Okell L, Jeanne I, Incardona S, Duval L, et al. Sub-microscopic malaria cases and mixed malaria infection in a remote area of high malaria endemicity in Rattanakiri province, Cambodia: implication for malaria elimination. Malar J. 2010;9:108. 
63. Bruce MC, Day KP. Cross-species regulation of malaria parasitaemia in the human host. Curr Opin Microbiol. 2002;5:431-7.

64. Bruce MC, Day KP. Cross-species regulation of Plasmodium parasitemia in semi-immune children from Papua New Guinea. Trends Parasitol. 2003;19:271-7.

65. Collins WE, Jeffery GM. Plasmodium malariae: parasite and disease. Clin Microbiol Rev. 2007;20:579-92.
66. Schumacher R-F, Spinelli E. Malaria in children. Mediterr J Hematol Infect Dis. 2012;4:e2012073

\section{Publisher's Note}

Springer Nature remains neutral with regard to jurisdictional claims in published maps and institutional affiliations.
Ready to submit your research? Choose BMC and benefit from:

- fast, convenient online submission

- thorough peer review by experienced researchers in your field

- rapid publication on acceptance

- support for research data, including large and complex data types

- gold Open Access which fosters wider collaboration and increased citations

- maximum visibility for your research: over $100 \mathrm{M}$ website views per year

At BMC, research is always in progress.

Learn more biomedcentral.com/submissions 